Research Paper

\title{
Nab-paclitaxel plus gemcitabine as first-line treatment for advanced pancreatic cancer: a systematic review and meta-analysis
}

\author{
Yiyin Zhang1,2,3,4* Jin $\mathrm{Xu}^{1,2,3,4^{*}}$, Jie Hua1,2,3,4* Jiang Liu1,2,3,4, Chen Liang1,2,3,4, Qingcai Meng1,2,3,4, Quanxing \\ $\mathrm{Ni}^{1,2,3,4}, \mathrm{Si} \mathrm{Shi}^{3 凶}$, Xianjun $\mathrm{Yu}^{1,2,3,4}$ \\ 1. Department of Pancreatic Surgery, Fudan University Shanghai Cancer Center, No. 270 Dong' An Road, Shanghai 200032, PR China \\ 2. Department of Oncology, Shanghai Medical College, Fudan University, No. 270 Dong'An Road, Shanghai 200032, PR China \\ 3. Shanghai Pancreatic Cancer Institute, No. 270 Dong'An Road, Shanghai 200032, PR China \\ 4. Pancreatic Cancer Institute, Fudan University, No. 270 Dong'An Road, Shanghai 200032, PR China \\ *These authors contributed equally to this work \\ $\square$ Corresponding authors: Xianjun Yu; Tel.: +86-021-64175590; Email: yuxianjun@fudanpci.org ¿ Si Shi; Tel.: +86-021-64031446; Email: shisi@fudanpci.org \\ () The author(s). This is an open access article distributed under the terms of the Creative Commons Attribution License (https://creativecommons.org/licenses/by/4.0/). \\ See http://ivyspring.com/terms for full terms and conditions.
}

Received: 2018.09.12; Accepted: 2019.06.19; Published: 2019.07.23

\begin{abstract}
To evaluate the effectiveness of nab-paclitaxel plus gemcitabine (NG) as a first-line treatment for advanced pancreatic cancer. A meta-analysis was performed to assess the impact on the objective response rate (ORR), survival rate and grade 3/4 adverse events. Of the 2,056 patients included from 26 studies, the median overall survival ranged from 6.9 months to 24.7 months, with a 1-year survival rate of $45.2 \%(95 \% \mathrm{Cl}: 35.8 \%-54.5 \%)$. The 6-month progression-free survival rate was $41.0 \%$ (95\% Cl: $30.5 \%-51.4 \%)$, and the ORR was $31.6 \%(95 \% \mathrm{Cl}: 26.7 \%-36.6 \%)$. Fifty locally advanced pancreatic cancer (LAPC) patients underwent surgery and had an R0 resection rate of $52.0 \%$. No death was caused by toxicity, and 1,329 grade 3/4 adverse events were reported in 1,353 patients. NG has been proven to reduce tumours with an acceptable toxicity profile in metastatic pancreatic cancer. This analysis further demonstrates the efficacy and safety of NG for treating LAPC.
\end{abstract}

Key words: nab-paclitaxel plus gemcitabine, advanced pancreatic cancer, meta-analysis.

\section{Introduction}

The prognosis for pancreatic cancer $(\mathrm{PC})$ remains poor, and by 2030, PC will become the second leading cause of cancer-related deaths in the United States [1]. Only approximately $20 \%$ of patients are suitable for resection when first diagnosed; the remaining $80 \%$ are diagnosed with locally advanced pancreatic cancer (LAPC) or metastatic pancreatic cancer (MPC). LAPC is deemed unresectable because direct operation might leave positive resection margins, which jeopardize overall survival (OS) to a degree similar to that in cases not involving resection [2]. Radical surgical resection remains the only curative treatment for PC, and it is used in LAPC patients after primary treatment; however, randomized controlled trials
(RCTs) studying systemic chemotherapy have been performed in this patient group. Nab-paclitaxel, an albumin-bound nanoparticle form of paclitaxel, has demonstrated significant clinical benefit over gemcitabine monotherapy for MPC by improving the intratumoural concentration of gemcitabine [3]. The efficacy and safety of nab-paclitaxel plus gemcitabine (NG) was validated in the MPACT study, which showed response rates of $23 \%$ and $35 \%$ survival at one year [4]. Several studies on the use of NG to treat advanced pancreatic cancer (APC) have emerged in recent years. Therefore, we performed a meta-analysis to evaluate NG as a first-line treatment for APC patients. 


\section{Materials and methods}

This study was performed according to the procedures of Preferred Reporting Items for Systematic Reviews and Meta-Analyses statement [5]. The primary outcome measure was the objective response rate (ORR), which was defined as the time from the initial NG treatment until a change in disease status. Secondary outcome measures were disease control rate (DCR); 1-year and 2-year survival rates; grade $3 / 4$ adverse events; post-NG surgical resection rate and $\mathrm{R} 0$ resection rate.

\section{Search strategy and study selection}

We searched for all eligible studies in PMC, PubMed, Embase, MEDLINE and Web of Science from inception to November 28, 2018. The regular NG regimen consisted of nab-paclitaxel $\left(100-125 \mathrm{mg} / \mathrm{m}^{2}\right)$ and gemcitabine $\left(1000 \mathrm{mg} / \mathrm{m}^{2}\right)$ on days 1,8 , and 15 every 28 days. Search terms were defined as (Abraxane OR nab-paclitaxel OR albumin-bound paclitaxel) AND gemcitabine AND pancreatic. The search results were limited to human studies in English only. Conference abstracts were included because some clinical trials related to APC have not yet been published as papers. The inclusion criteria were as follows: (1) eligible patients diagnosed with APC; (2) patients did not receive surgery, but adjuvant chemo(radiation)therapy was allowed if received at least 6 months prior to NG treatment; (3) NG was accepted as first-line treatment without any other concurrent chemo(radiation)therapy; (4) non-clinical research, including reviews, meta-analysis, case reports, systematic reviews, basic experiments and letters to editors, was excluded.

\section{Data extraction and quality assessment}

Two independent reviewers (Yiyin Zhang and Jie Hua) designed the search strategy and assessed abstract eligibility. Disagreements were settled by discussion, and a consensus was achieved. Information extracted from related studies included the following: title, first author's name, number of eligible patients, tumour stage, ORR, DCR, progression-free survival (PFS), 6-month PFS rate, OS, 1-year and 2-year survival rates, surgical conversion rate and $\mathrm{R} 0$ rate. If progression or survival data were not provided in the text but only in graphs and figures, Engauge Digitizer version 4.1 (http://digitizer.source-forge.net/) was used to extract numerical values.

To assess the quality of the included studies with full text, the Newcastle-Ottawa Scale (NOS) was applied by 2 independent reviewers. RCTs were evaluated according to their JADAD score for the following: randomization, double blinding, withdrawals and dropouts. Scores ranged from 0 to 5, and $\geq 3$ was considered high-quality literature [6]. Non-RCTs were evaluated separately and judged primarily on 3 parameters: selection of the study groups, comparability of the groups and outcomes of cohort studies. A maximum of 9 points was assigned to each study, and scores of 5 to 9 were considered high quality [7].

\section{Statistical analysis}

All of the analyses were performed using the STATA SE 12.0 package (StataCorp, College Station, Texas, USA) and Comprehensive Meta-analysis 2.0 (Biostat, New Jersey, USA). We used the random-effects model if $\mathrm{I}^{2}>50 \%$ or $P<0.1$; otherwise, the fixed-effects model was applied. The results were considered statistically significant at $P<0.05$. Heterogeneity was determined by $\chi^{2}$ tests and $\mathrm{I}^{2}$ statistics as described by Higgins and Thompson. Subgroup analysis was performed according to LAPC and MPC diagnosis; NG and FOLFIRINOX (FFX) treatment for MPC; and the efficacy of NG and non-NG treatment in MPC.

\section{Results}

\section{Literature search and study characteristics}

In PMC, PubMed, Embase, MEDLINE and Web of Science, we identified 4,075 studies, among which 3,221 were excluded based on their abstract, and 854 were potentially appropriate. We screened the remaining 854 studies and excluded 828 studies for the reasons listed in Figure 1. Thus, we included 26 articles examining a total of 2,056 PC patients in this systematic review and meta-analysis [8-33]. Fifteen studies were retrospective, and 11 studies were prospective. Among all included patients, 210 had LAPC, and 1,846 had MPC. The characteristics of all of the included studies meeting the inclusion criteria for this meta-analysis are provided in Table 1 and Table 2.

\section{Primary endpoint}

According to single arm analysis, the overall ORR in 24 accessible studies was 31.6\% (95\% CI: 26.7\% - 36.6\%) for APC. In the subgroup analysis, the ORR was $51.3 \%$ (95\% CI: $30.6 \%-71.9 \%)$ in 3 LAPC studies and $29.5 \%$ (95\% CI: $24.7 \%-34.4 \%$ ) in 21 MPC studies (Figure 2). MPC patients in the non-NG group had an ORR of $25.3 \%$ ( $95 \%$ CI: $13.7 \%-37.0 \%$ ). Four studies compared the efficacy of NG and FFX as first-line treatments for MPC patients, and the ORR of the FFX group was $33.2 \%$ (95\% CI: $14.3 \%-52.1 \%$ ), which was lower than the $37.7 \%$ ORR (95\% CI: $32.2 \%-43.3 \%)$ in the NG group. 


\section{Secondary endpoints}

For LAPC, the DCR generated from 3 studies was $87.4 \%$ (95\%CI: $75.8 \%$ - 98.9\%; Figure 3). Fifty $(24.6 \%)$ patients underwent surgical resection after 4 cycles of NG administration, and the R0 rate was $52.0 \%(26 / 50)$, ranging from $44.0 \%$ to $100.0 \%$. For MPC, the DCR generated from 15 studies was $66.7 \%$ (95\%CI: $56.4 \%$ - 77.1\%; Figure 3); the median OS ranged from 6.9 months to 14.7 months across 19 studies. The 1-year survival rate evaluated for 10 studies was $45.2 \%$ (95\%CI: 35.8\% -54.5\%; Figure 4A), the 2-year survival rate evaluated for 3 studies was $6.6 \%$ (95\%CI: $0.1 \%-13.1 \%)$. The number of studies evaluating the 2-year survival rate decreased because most studies terminated before 24 months. The median PFS ranged from 4.0 months to 8.4 months across 18 studies, and the 6-month PFS rate was $41.0 \%$ (95\%CI: 30.5\% - 51.4\%; Figure 4B) for 9 studies. In the non-NG group, the DCR for 3 studies was $42.0 \%$ (95\% CI: $7.8 \%-76.3 \%)$, and the 1-year survival rate was $28.6 \%$ (95\%CI: $16.5 \%-40.7 \%)$.

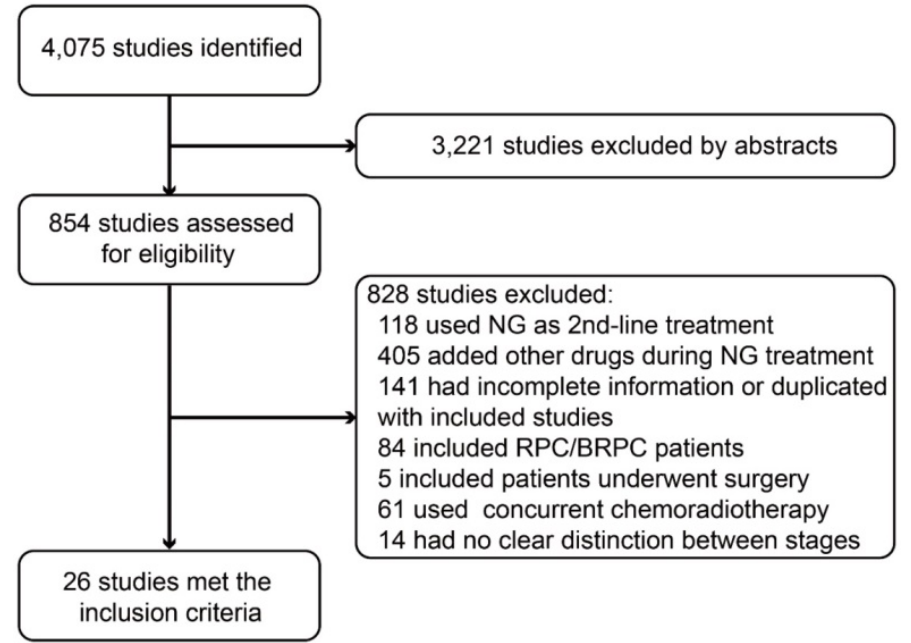

Figure 1. Flowchart of the search process of our study. Abbreviations: NG=nab-paclitaxel plus gemcitabine; RPC=resectable pancreatic cancer; $B R P C=$ borderline resectable pancreatic cancer.

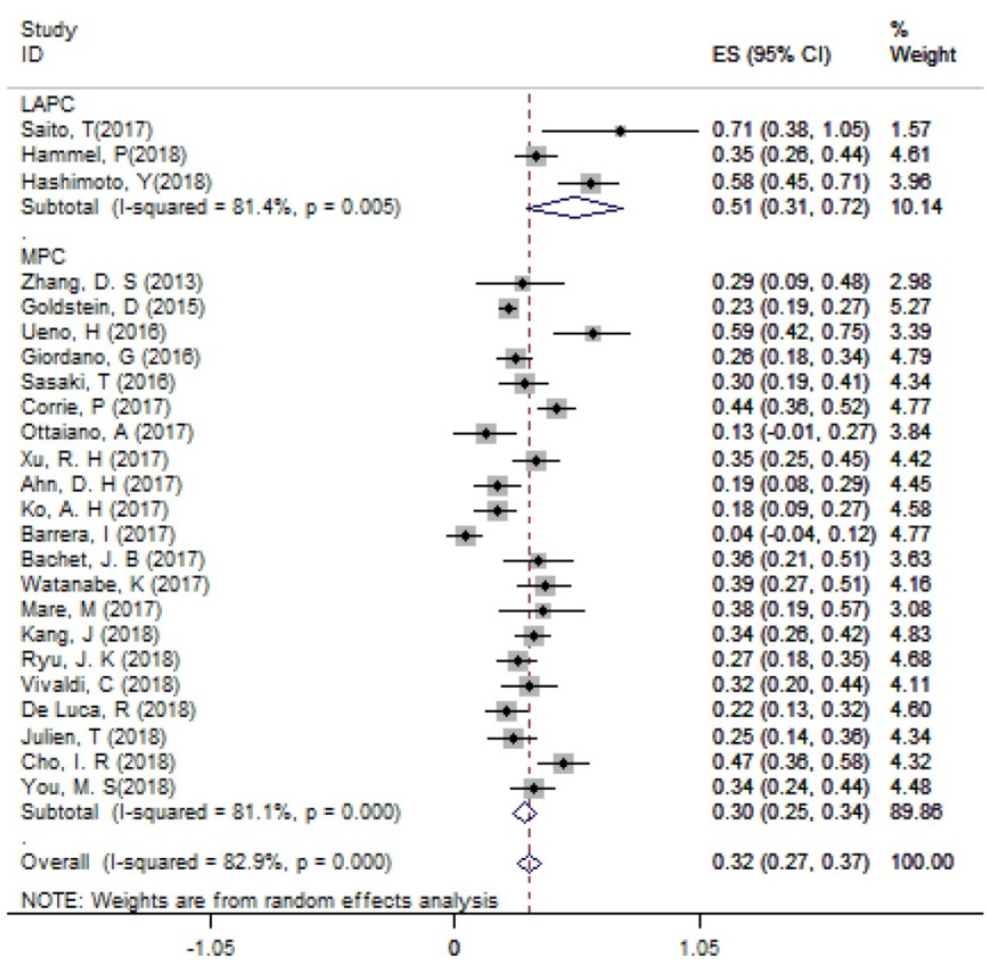

Figure 2. The overall ORR for APC. Abbreviations: ORR=objective response rate; $A P C=$ advanced pancreatic cancer 
Table 1. Characteristics of studies included in the meta-analysis.

\begin{tabular}{|c|c|c|c|c|c|c|c|c|c|c|c|}
\hline Study & Year & $\begin{array}{l}\text { No. of } \\
\text { patients }\end{array}$ & $\begin{array}{l}\text { Stag } \\
\text { e }\end{array}$ & $\begin{array}{l}\text { OR } \\
\mathbf{R}\end{array}$ & $\begin{array}{l}\text { DC } \\
\mathbf{R}\end{array}$ & $\begin{array}{l}\text { Median OS } \\
\text { (months) }\end{array}$ & $95 \% \mathrm{CI}$ & $\begin{array}{l}\text { 1-year survival } \\
\text { rate }\end{array}$ & $\begin{array}{l}\text { Median PFS } \\
\text { (months) }\end{array}$ & $95 \%$ CI & $\begin{array}{l}\text { 6-month PFS } \\
\text { rate }\end{array}$ \\
\hline \multicolumn{12}{|l|}{ LAPC } \\
\hline Saito & 2017 & 7 & III & 0.71 & 0.94 & 13.30 & $\begin{array}{l}11.30- \\
15.30\end{array}$ & 0.86 & - & - & - \\
\hline Hammel & 2018 & 106 & III & 0.35 & 0.78 & - & - & - & 10.20 & - & - \\
\hline Volker & 2018 & 42 & III & - & 0.93 & - & - & - & - & - & - \\
\hline Hashimoto & 2018 & 55 & III & 0.58 & - & 24.70 & 15.50 - NR & - & - & - & - \\
\hline \multicolumn{12}{|l|}{ MPC } \\
\hline Zhang & 2013 & 21 & IV & 0.29 & 0.81 & 12.17 & $9.49-14.84$ & 0.65 & 4.43 & $4.01-4.83$ & 0.33 \\
\hline Goldstein & 2015 & 431 & IV & 0.23 & 0.48 & 8.70 & $7.89-9.69$ & 0.35 & 5.50 & $4.50-5.90$ & - \\
\hline Giordano & 2016 & 118 & IV & 0.26 & - & 11.00 & $9.58-12.41$ & - & 7.00 & $5.96-8.03$ & - \\
\hline Sasaki & 2016 & 70 & IV & 0.30 & 0.82 & 10.40 & - & - & 5.90 & - & - \\
\hline Ueno & 2016 & 34 & IV & 0.59 & 0.94 & 13.50 & 10.60 - NR & 0.62 & 6.50 & $5.10-8.30$ & 0.47 \\
\hline Corrie & 2017 & 146 & IV & 0.44 & - & 10.10 & - & 0.29 & 5.80 & - & 0.47 \\
\hline Mare & 2017 & 26 & IV & 0.38 & 0.53 & 9.00 & $2.00-18.00$ & - & 6.00 & $\begin{array}{l}1.00- \\
12.00\end{array}$ & - \\
\hline Bachet & 2015 & 39 & IV & 0.36 & 0.62 & 9.20 & $6.00-13.60$ & - & 4.90 & $2.10-7.70$ & - \\
\hline Ottaiano & 2017 & 23 & IV & 0.13 & 0.44 & - & - & - & - & - & - \\
\hline $\mathrm{Xu}$ & 2017 & 83 & IV & 0.35 & 0.55 & 9.30 & - & 0.32 & 5.50 & $5.29-7.16$ & 0.28 \\
\hline Ahn & 2017 & 57 & IV & 0.19 & - & 10.00 & $5.90-13.00$ & 0.42 & 5.40 & $4.10-7.40$ & 0.46 \\
\hline Barrera & 2017 & 24 & IV & 0.04 & 0.33 & - & - & - & - & - & - \\
\hline Ko & 2017 & 66 & IV & 0.18 & 0.50 & 6.90 & - & 0.20 & 6.80 & - & 0.27 \\
\hline Watanabe & 2017 & 65 & IV & 0.34 & 0.92 & 14.00 & 12.20 - NR & 0.67 & 6.50 & $6.10-7.90$ & - \\
\hline Cho & 2018 & 81 & IV & 0.47 & 0.84 & 12.10 & 10.70 - NR & 0.55 & 8.40 & $5.00-11.80$ & 0.48 \\
\hline Julien & 2018 & 62 & IV & 0.25 & - & - & - & - & - & - & 0.23 \\
\hline Vivaldi & 2018 & 57 & IV & 0.32 & - & 10.60 & - & - & 6.20 & - & - \\
\hline Ryu & 2018 & 101 & IV & 0.27 & 0.72 & 14.70 & - & - & 7.30 & - & - \\
\hline Kang & 2018 & 149 & IV & 0.34 & - & 11.40 & - & - & 6.80 & - & - \\
\hline $\begin{array}{l}\text { Pacheco-Barci } \\
\text { a }\end{array}$ & 2018 & 25 & IV & - & - & 14.00 & - & - & 8.00 & - & - \\
\hline De Luca & 2018 & 80 & IV & 0.23 & 0.55 & 8.00 & $7.13-8.86$ & - & 5.00 & $3.86-6.13$ & - \\
\hline You & 2018 & 88 & IV & 0.34 & 0.84 & 14.20 & $\begin{array}{l}11.80- \\
20.30\end{array}$ & 0.57 & 8.40 & $\begin{array}{l}7.10- \\
13.20\end{array}$ & 0.69 \\
\hline
\end{tabular}

Abbreviations: $\mathrm{ORR}=$ objective overall survival; Median OS=median overall survival; $\mathrm{CI}=$ confidence interval; Median PFS=median progression-free survival; $\mathrm{NR}=$ not reached.

Table 2. Characteristics of studies included in the non-NG group.

\begin{tabular}{|c|c|c|c|c|c|c|c|c|}
\hline Study & Regimen & No. of patients & ORR & DCR & Median OS & 1-year survival rate & Median PFS & 6-month PFS rate \\
\hline Goldstein & Gemcitabine & 430 & 0.07 & 0.35 & 6.60 & 0.22 & 3.70 & - \\
\hline Ko & $\mathrm{NG}+$ apatorsen & 66 & 0.18 & - & 5.30 & 0.22 & 2.70 & 0.27 \\
\hline Barrera & FFX & 10 & 0.00 & 0.10 & - & - & - & - \\
\hline Bachet & $\begin{array}{l}\mathrm{N}+\text { simplified leucovorin } \\
\text { and fluorouracil }\end{array}$ & 75 & 0.35 & - & 11.60 & - & 6.40 & - \\
\hline Vivaldi & mFFX & 81 & 0.36 & - & 11.50 & - & 6.40 & - \\
\hline Pacheco-Barcia & mFFX & 21 & - & - & 14.00 & - & 8.00 & - \\
\hline Kang & FFX & 159 & 0.34 & - & 9.60 & - & 5.10 & - \\
\hline Watanabe & $\mathrm{mFFX}$ & 70 & 0.29 & 0.79 & 11.50 & 0.44 & 5.70 & - \\
\hline Julien & FIRGEMAX & 65 & 0.40 & - & 15.80 & - & - & 0.45 \\
\hline
\end{tabular}

Abbreviations: $\mathrm{ORR}=$ objective response rate; $\mathrm{DCR}=$ disease control rate; Median OS=median overall survival; Median PFS=median progression-free survival;

$\mathrm{NG}=$ nab-paclitaxel plus gemcitabine; FFX=FOLFIRINOX; N=nab-paclitaxel; mFFX=modified FOLFIRINOX; FIRGEMAX=nab-paclitaxel plus gemcitabine and FOLFIRI.

Twenty-one studies used the same NG dose as the MPACT trial, except 1 study including 57 patients who used a modification of the NG dose described as gemcitabine $\left(1000 \mathrm{mg} / \mathrm{m}^{2}\right)$ and nab-paclitaxel (125 $\mathrm{mg} / \mathrm{m}^{2}$ ) on days 1 and 15 of every 28 days [30]. The median OS of this study was 10.0 months (ranging from 5.9 to 13.0 months), and the median PFS was 5.4 months (ranging from 4.1 to 7.4 months) [15]. One study changed only the dose of nab-paclitaxel to 120 $\mathrm{mg} / \mathrm{m}^{2}$. The median number of NG-administered cycles ranged from 2 to 9 [8]. The FFX regimen was as described in the PRODIGE 4 trial, which was a 2-h intravenous infusion of oxaliplatin $\left(85 \mathrm{mg} / \mathrm{m}^{2}\right)$ followed by a 2-h intravenous infusion of leucovorin $\left(400 \mathrm{mg} / \mathrm{m}^{2}\right)$, and irinotecan was given 30 minutes later $\left(180 \mathrm{mg} / \mathrm{m}^{2}\right)$ via 90 -minute intravenous infusion. Fluorouracil was given immediately after via intravenous bolus at a dose of $400 \mathrm{mg} / \mathrm{m}^{2}$ followed by a continuous intravenous infusion of $2400 \mathrm{mg} / \mathrm{m}^{2}$ over a 46-hour period biweekly [34]. The modified usage of FFX was not elaborated in the methods of the included studies.

For LAPC, 113 patients in 2 studies were analysed for grade $3 / 4$ adverse events. Two studies 
used a full dose of NG as described in the MPACT trial, and 76 grade $3 / 4$ adverse events were reported. For MPC, 1,183 patients in 14 studies received the full NG dose that the MPACT trial prescribed, and 833 haematological (Table 3) and 386 non-haematological grade $3 / 4$ adverse events (Table 4 ) were reported, with neutropenia and leukopenia being the most common adverse events. One study used a modified NG dose (on days 1 and 15 every 28 days), and 33 grade $3 / 4$ adverse events were reported [15]. One study that used an NG dose of $120 \mathrm{mg} / \mathrm{m}^{2}$ reported 5

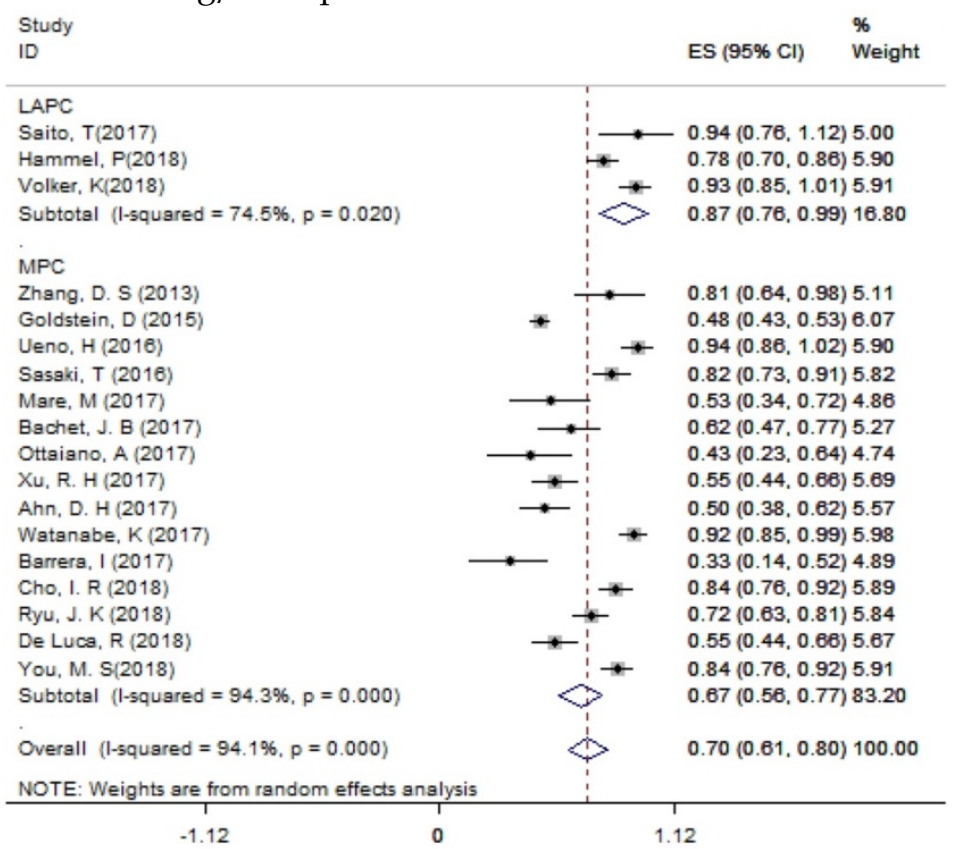

Figure 3. The DCR for LAPC and MPC. Abbreviations: $D C R=$ disease control rate; LAPC=locally advanced pancreatic cancer; $M P C=$ metastatic pancreatic cancer.

Table 3. Grade 3/4 haematological toxicities.

\begin{tabular}{ll}
\hline Haematological toxicities & Study (number of events) \\
\hline Leukopenia & Saito (3), Goldstein (127), Ueno (19), Xu (28) \\
Anemia & Hammel (12), Goldstein (56), Ueno (5), Cho (12), Xu (12), Ahn (8), Bachet (5), Ryu (23), You (19) \\
Thrombocytopenia & Goldstein (52), Ottaiano (2), Ueno (5), Zhang (1), Cho (5), Xu (8), Ahn (1), Bachet (7), Mare (4), You (5) \\
Neutropenia & Hammel (45), Goldstein (153), Ottaiano (5), Ueno (24), Zhang (2), Cho (38), Xu (27), Ahn (11), Bachet (12), Ryu 455 \\
& $(41)$, Pacheco-Barcia (3), Watanabe (29), Julien (31), You (34) \\
Lymphocytopenia & Ueno (5), De Luca (11) \\
Febrile neutropenia & Ueno (2), Zhang (2), Ahn (1), De Luca (10), You (5) \\
\hline
\end{tabular}

Table 4. Grade 3/4 non-haematological adverse events.

\begin{tabular}{ll}
\hline Non-haematological toxicities & Study (number of events) \\
\hline $\begin{array}{l}\text { Liver dysfunction } \\
\text { Stomatitis }\end{array}$ & Ueno (1) \\
Neuropathy & De Luca (8), Bachet (7) \\
& Hammel (4), Goldstein (71), Ottaiano (7), Ueno (4), Zhang (1), Cho (15), Ahn (1), Bachet (4), Ryu (15), Watanabe 162 \\
Diarrhea & Goldstein (24), Ueno (2), Watanabe (1), Julien (2), You (1) \\
Appetite loss & Ueno (1) \\
Rash & Ueno (1), Julien (14) \\
Bilateral cellulitis & Saito (1) \\
Fatigue & Hammel (11), Goldstein (73), Ottaiano (4), Xu (11), Ahn (4), De Luca (27), Mare (2), Julien (2) \\
Nausea and vomit & Ueno (1), Cho (16), Ahn (1), You (3) \\
ALP abnormality & Ottaiano (3), Bachet (5) \\
Hyperglycemia & Ottaiano (2) \\
Hyponatremia & Ueno (2) \\
Hyperbilirubinemia & Ottaiano (3)
\end{tabular}

grade $3 / 4$ adverse events. Eight studies did not report toxicity data. No deaths were attributed to NG treatment [8]. Four hundred and twenty-four (65.1\%) grade 3/4 adverse events were reported among 651 MPC patients treated with a non-NG regimen.

\section{Quality assessment}

The results of the NOS scale and JADAD score showed that the quality of the included studies ranged from moderate to high (Table 5). 


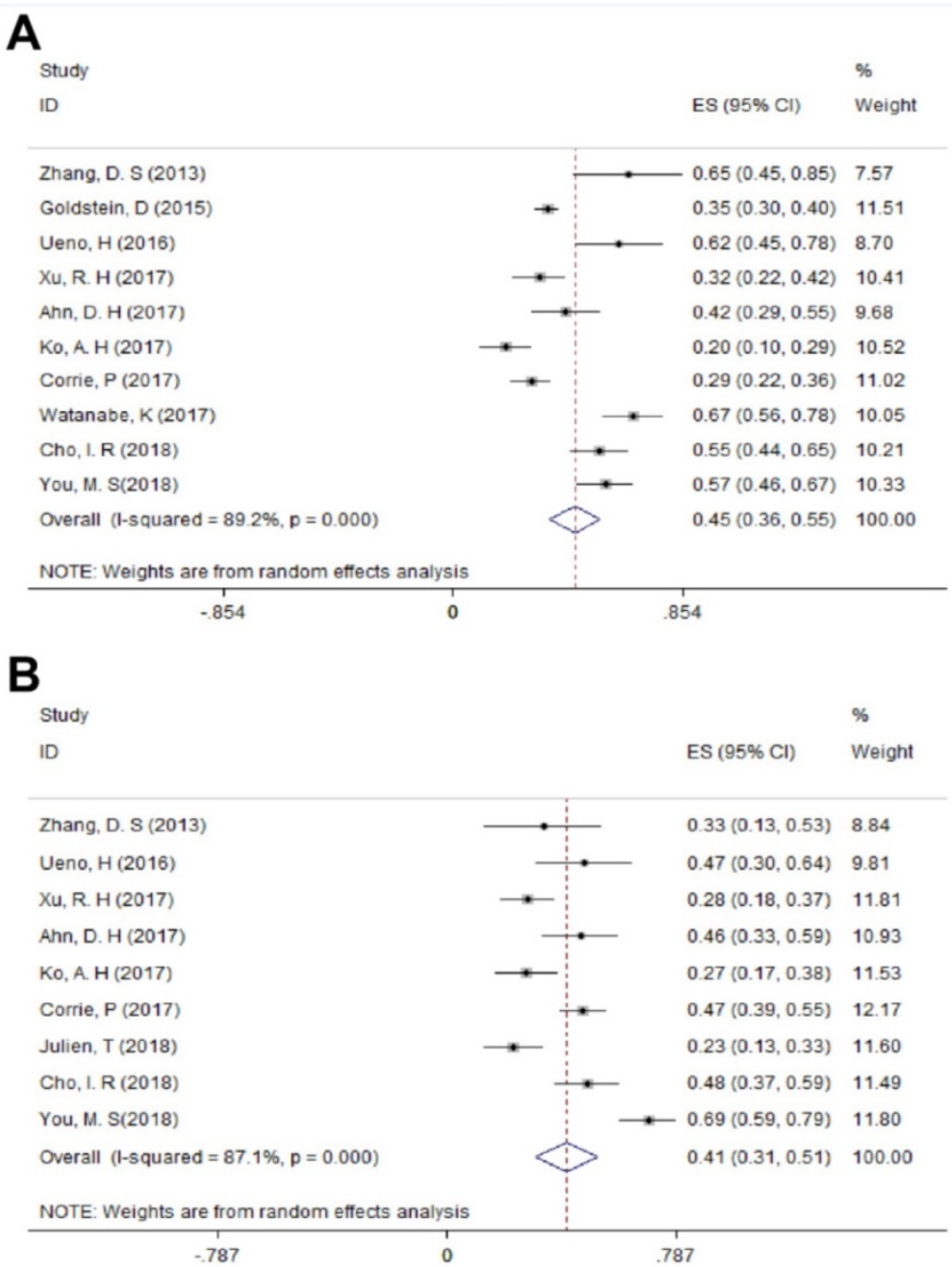

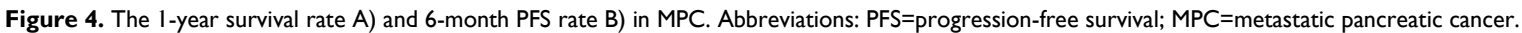

\section{Discussions}

Numerous studies have focused on the efficacy and safety of NG for APC patients, although no definitive conclusions have been identified to date. This is the first meta-analysis summarizing the use of NG as a first-line APC treatment. Although the combination of nab-paclitaxel and gemcitabine was a milestone in MPC treatment, there remains a paucity of data regarding the use of NG to treat APC.

In 2013, Von Hoff DD and colleagues reported the first open-label randomized phase III study that included 431 MPC patients treated with nab-paclitaxel followed by gemcitabine, which achieved a median OS of 8.5 months (95\% CI: 7.5 - 9.5 months) compared with 6.7 months (95\% CI: 6.0 - 7.2 months) for those treated with gemcitabine alone. The 1-year survival rate exceeded $30 \%$ and reached $35 \%$, significantly outperforming the $22 \%$ rate reported for gemcitabine monotherapy (GEM) $(P<0.001)$. The rates of peripheral neuropathy and myelosuppression were increased but acceptable and reversible. Since then, an increasing number of case reports and clinical studies assessing NG treatment for APC have been published. MPACT is the largest study exploring the efficacy and side effects in the MPC population thus far. Other studies with a smaller population $(n=1415)$ further confirmed the effectiveness and safety of NG, with a median OS ranging from 6.9 to 14.7 months and a 6 -month PFS rate of $41.0 \%$. Before the advent of NG, FFX was verified as an active APC regimen and exhibited a median OS of 4.3 months longer than GEM. However, the FFX study excluded patients older than 75 years and patients with an Eastern Cooperative Oncology Group status of 2, which might influence the results because performance status was an independent predictor of survival [4]. Ventriglia J et al suggested that NG was effective and safe in an unselected population of elderly patients based on an evaluation of 46 patients with a median age older than 73 years [35]. New studies directly comparing FFX and NG reported an ORR of $33.2 \%$ in the FFX group and $37.7 \%$ in the NG group. Kang J et al found that patients had a longer median OS in the NG group 
than in the FFX group (11.4 vs 9.6 months; $P=0.002$ ), especially patients older than 65 years; these patients also had a higher Charlson score and peritoneal metastasis [36]. NG also caused less grade 3/4 neutropenia, diarrhoea and peripheral neuropathy incidences than modified FFX treatment [29]. Although NG caused considerable peripheral neuropathy incidence, patients with grade $3 / 4$ recovered to grade 1 or lower in a median of 29 days, which was more rapid than patients with cumulative oxaliplatin toxicity [4]. Moreover, the development of peripheral neuropathy was associated with an improved median OS (grade 3 vs grade 0: 14.9 vs 5.9 months, $\mathrm{HR}=0.33 ; P<0.0001)$. The result was inspiring for clinical physicians, as it provided reliable evidence for choosing NG as first-line chemotherapy for patients with underlying medical conditions. The patients included in the non-NG group in our analysis showed a grade $3 / 4$ toxicity rate of $65.1 \%$, mainly because some data for non-haematological events were not able to be extracted. The difference in CA19-9 levels should also be considered when selecting treatments for MPC patients because those with an abnormal CA19-9 level had better outcomes with gemcitabine than with FFX [34]. In the exploratory MPACT study, CA19-9 levels were reduced significantly more in the NG group than in the gemcitabine-alone group, and the CA19-9 decrease might help identify patients with a survival benefit by week eight [37]. The prognosis was worse for patients with normal CA19-9 levels than for those with decreased CA19-9 levels, indicating that the level of CA19-9 reduction might screen out patients insensitive to NG. This spares NG-insensitive patients from unnecessary side effects, preserving their strength for other treatments and improving their quality of life (QoL). A recently published study used propensity-matched analysis to compare the effectiveness of FFX and NG in the neoadjuvant setting for resectable and borderline resectable PC. The reduction of $\mathrm{pN} 1$ disease and improvement of 4.9-month OS in the FFX group compared with the NG group indicated that more attention should be paid to the selection of specific patient groups that would actually benefit from either FFX or NG treatment [38]. Attempts have been made to improve the efficacy and reduce the side effects of sequential therapy. The PRODIGE 37-FIRGEMAX trial provided a 2-month alternate MPACT regimen and 2-month FOLFIRI regimen for patients with a performance status (PS) of 0-2. The results showed that peripheral neuropathy decreased 35\% compared to that found for the MPACT regimen, and a 60\% 6-month PFS rate was achieved. FIRGEMAX appeared to be feasible and effective for MPC with a tolerable toxicity profile and guaranteed treatment for more than 2 months [17].

Table 5. Assessment of study quality.

\begin{tabular}{|c|c|c|c|c|}
\hline \multicolumn{5}{|c|}{ Newcastle-Ottawa scale for non-randomized controlled studies } \\
\hline Study & Selection (0-4) & $\begin{array}{l}\text { Comparability } \\
(0-2)\end{array}$ & Outcome (0-3) & Total \\
\hline Saito & 3 & 1 & 2 & 6 \\
\hline Zhang & 3 & 1 & 2 & 6 \\
\hline De Luca & 2 & 1 & 2 & 5 \\
\hline Barrera & 3 & 1 & 3 & 7 \\
\hline Vivaldi & 3 & 1 & 2 & 6 \\
\hline Ryu & 2 & 1 & 2 & 5 \\
\hline $\begin{array}{l}\text { Pacheco-B } \\
\text { arcia }\end{array}$ & 4 & 1 & 2 & 7 \\
\hline Watanabe & 4 & 1 & 2 & 7 \\
\hline Mare & 2 & 1 & 2 & 5 \\
\hline Giordano & 3 & 1 & 2 & 6 \\
\hline Sasaki & 2 & 1 & 2 & 5 \\
\hline Kang & 3 & 1 & 2 & 6 \\
\hline Hashimoto & 2 & 1 & 2 & 5 \\
\hline Ottaiano & 3 & 1 & 2 & 6 \\
\hline $\mathrm{Xu}$ & 3 & 1 & 2 & 6 \\
\hline Ahn & 3 & 1 & 2 & 6 \\
\hline Cho & 3 & 2 & 1 & 6 \\
\hline You & 2 & 2 & 1 & 5 \\
\hline \multicolumn{5}{|c|}{ JADAD score for randomized controlled studies } \\
\hline Study & $\begin{array}{l}\text { Randomizatio } \\
\text { n (0-2) }\end{array}$ & $\begin{array}{l}\text { Double } \\
\text { blinding (0-2) }\end{array}$ & $\begin{array}{l}\text { Withdrawals and } \\
\text { dropouts }(0-1)\end{array}$ & Total \\
\hline Corrie & 1 & 1 & 1 & 3 \\
\hline Hammel & 1 & 1 & 1 & 3 \\
\hline Julien & 2 & 1 & 1 & 4 \\
\hline Bachet & 2 & 2 & 1 & 5 \\
\hline Volker & 2 & 1 & 1 & 4 \\
\hline Ueno & 1 & 1 & 1 & 3 \\
\hline Ko & 2 & 2 & 1 & 5 \\
\hline Goldstein & 2 & 2 & 1 & 5 \\
\hline
\end{tabular}

Patients with LAPC rarely underwent surgical resection because the 2016 ASCO guidelines recommended that treatment for LAPC should focus on local control and QoL, and no clear evidence supported one regimen over another due to the lack of RCTs comparing different regimens in this specific population [39]. However, Georgios G et al retrospectively included 415 LAPC patients who received FFX- and gemcitabine-based chemotherapy, and the results showed that patients who underwent resection (20\%) after 5 months of neoadjuvant chemotherapy had a median OS of 35.3 months (similar to patients with resectable disease) compared with 16.2 months for those who progressed after neoadjuvant chemotherapy. Additionally, patients who received $\mathrm{N} 0$ and $\mathrm{R} 0$ resection lived significantly longer than those who received N1-2 and R1 resection. However, no significant difference between neoadjuvant treatments was observed in that study [40], indicating that the efficacy of neoadjuvant chemotherapy could help predict the prognosis of LAPC patients. In the studies that we pooled for this 
analysis, $24.6 \%$ of LAPC patients completed surgical conversion after NG with an R0 rate of $52.0 \%$. In 2 studies comprising 113 patients, $76(67 \%)$ grade 3/4 adverse events were reported. These results were similar to those in LAPC patients who received FFX but had a lower R0 rate $(24.6 \%$ vs $28 \% ; 52.0 \%$ vs $74 \%$; $67 \%$ vs $60 \%$ ) [41]. RCTs are required to compare the efficacy and safety of FFX and NG for treating LAPC. The current ongoing phase II LAPACT included 107 LAPC patients treated with NG, and preliminary results indicated that CA19-9 levels decreased by $\geq$ $50 \%$ in $75.3 \%$ patients with a median time to failure of 8.8 months, which was 2.2 months longer than expected. The LAPACT trial intended to recruit 220 patients to evaluate NG as an optimal first-line plan to improve the surgical conversion rate in LAPC [12].

The role that chemoradiotherapy plays in APC is ambiguous. The LAP 07 trial showed that LAPC patients who received continued chemotherapy after controlled disease exhibited a longer median survival than those who proceeded to chemoradiotherapy [42]. However, a recent study based on 13,004 LAPC patients in the National Cancer Database demonstrated that chemoradiotherapy was associated with a superior OS compared with chemotherapy alone $(\mathrm{HR}=0.79 ; 95 \% \mathrm{CI}: 0.76-0.83 ; P<0.001)$ [43]. Yamada $S$ et al designed a chemoradiotherapy protocol using NG in combination with 50.4 Gy, which had a $50 \%(6 / 12)$ surgical conversion rate and a $100 \%$ 1-year survival rate with only one patient experiencing grade 4 toxicity [44]. Stereotactic body radiotherapy (SBRT) has feasible, safe and effective properties when used to treat unresectable patients with comorbidities that preclude surgery, intensive chemotherapy and conventional radiation therapy [45]. These recommendations were also supported by a large retrospective study of 8,450 LAPC patients who showed a survival advantage for SBRT treatment compared with CRT $(\mathrm{HR}=0.84, P<0.001)$ [46]. Future randomized trials should consider SBRT for continuing treatment after NG for LAPC patients because no treatment can be substituted for surgical resection; improving the surgical conversion rate is of utmost importance.

Grade 3/4 adverse events pooled from prospective studies were higher than those from retrospective studies, indicating that the pooled adverse event rate might be more accurate in prospective studies. The modified NG dose resulted in nearly half the grade 3/4 adverse event rate as the full dose with similar median OS and PFS rates, thus providing a reliable treatment option for those with a poor PS. The 6-month QoL for the gemcitabine treatment arm was two times higher than that for the FFX arm (66\% vs 31\%, respectively; $P<0.001)$, in accordance with a recently published study showing that NG was associated with relatively tolerable toxicities, especially for MPC, which generally has a poorer PS and convenient free genetic testing, compared with FFX [47].

Nevertheless, several limitations should be mentioned. First, individual information was not presented in some of the included studies, which might contain unknown prognostic factors, combinations of other medications and additional comorbidities. Second, not all of the included studies were randomized clinical trials, leading to potential bias. Third, the PFS might be biased because only prospective studies used standardized imaging to evaluate treatment efficacy; the retrospective studies included in this analysis did not provide similar imaging.

The findings in this analysis may benefit a substantial proportion of APC patients, as LAPC and MPC account for most PC cases. The surgical conversion rate and $\mathrm{R} 0$ resection rate after $\mathrm{NG}$ treatment were considerable in LAPC. NG showed mild side effects in MPC patients compared with FFX. However, NG efficacy in treating LAPC is not conclusive due to the insufficient sample sizes of the included trials. Therefore, more high-quality RCTs with larger sample sizes are required to reveal true NG efficacy.

\section{Abbreviations}

PC: pancreatic cancer; LAPC: locally advanced pancreatic cancer; MPC: metastatic pancreatic cancer; OS: overall survival; RCTs: randomized controlled trials; NG: nab-paclitaxel plus gemcitabine; APC: advanced pancreatic cancer; ORR: objective response rate; DCR: disease control rate; GEM: gemcitabine; FFX: FOLFIRINOX; QoL: quality of life; SBRT: stereotactic body radiotherapy; PS: performance status; NOS: Newcastle-Ottawa scale.

\section{Acknowledgements}

This study was supported in part by the National Science Foundation for Distinguished Young Scholars of China (Grant Number 81625016) and the Shanghai Sailing Program (Grant Number 17YF1402500).

\section{Competing Interests}

The authors have declared that no competing interest exists.

\section{References}

1. Gillen S, Schuster T, Meyer Zum Buschenfelde C, Friess H, Kleeff J. Preoperative/neoadjuvant therapy in pancreatic cancer: a systematic review and meta-analysis of response and resection percentages. PLoS Med. 2010; 7: e1000267. 
2. Chandrasegaram MD, Goldstein D, Simes J, Gebski V, Kench JG, Gill AJ, et al. Meta-analysis of radical resection rates and margin assessment in pancreatic cancer. Br J Surg. 2015; 102: 1459-72.

3. Frese KK, Neesse A, Cook N, Bapiro TE, Lolkema MP, Jodrell DI, et al. nab-Paclitaxel potentiates gemcitabine activity by reducing cytidine deaminase levels in a mouse model of pancreatic cancer. Cancer Discov. 2012; 2: $260-9$

4. Von Hoff DD, Ervin T, Arena FP, Chiorean EG, Infante J, Moore M, et al. Increased survival in pancreatic cancer with nab-paclitaxel plus gemcitabine. N Engl J Med. 2013; 369: 1691-703.

5. Liberati A, Altman DG, Tetzlaff J, Mulrow C, Gøtzsche PC, Ioannidis JPA, et al. The PRISMA Statement for Reporting Systematic Reviews and Meta-Analyses of Studies That Evaluate Health Care Interventions: Explanation and Elaboration. Epidemiology Biostatistics \& Public Health. 2009; 6: e1-e34

6. Olivo SA, Macedo LG, Gadotti IC, Fuentes J, Stanton T, Magee DJ. Scales to assess the quality of randomized controlled trials: a systematic review. Phys Ther. 2008; 88: 156-75.

7. Ownby RL, Crocco E, Acevedo A, John V, Loewenstein D. Depression and risk for Alzheimer disease: systematic review, meta-analysis, and metaregression analysis. Arch Gen Psychiatry. 2006; 63: 530-8.

8. Zhang DS, Wang DS, Wang ZQ, Wang FH, Luo HY, Qiu MZ, et al. Phase I/II study of albumin-bound nab-paclitaxel plus gemcitabine administered to Chinese patients with advanced pancreatic cancer. Cancer chemotherapy and pharmacology. 2013; 71: 1065-72.

9. Ottaiano A, Capozzi M, C DED, C VONA, E DIG, Nasti G, et al. Nab-Paclitaxel and Gemcitabine in Advanced Pancreatic Cancer: The One-year Experience of the National Cancer Institute of Naples. Anticancer Res. 2017; 37: 1975-8.

10. Ueno H, Ikeda M, Ueno M, Mizuno N, Ioka T, Omuro Y, et al. Phase I/II study of nab-paclitaxel plus gemcitabine for chemotherapy-naive Japanese patients with metastatic pancreatic cancer. Cancer chemotherapy and pharmacology. 2016; 77: 595-603.

11. Saito T, Toyoki Y, Ishido K, Kudo D, Kimura N, Wakiya T, et al. Efficacy of gemcitabine plus nab-paclitaxel combination therapy for locally advanced unresectable pancreatic cancer. Pancreatology. 2016; 16: S57.

12. Hammel P, Lacy J, Portales F, Sobrero AF, Cid RAP, Mozo JLM. Phase II LAPACT trial of nab-paclitaxel (nab-P) plus gemcitabine $(G)$ for patients with locally advanced pancreatic cancer (LAPC). Journal of Clinical Oncology. 2018; 36 (Suppl 4): S204.

13. Corrie P, Qian W, Basu B, Jodrell DI, Falk S, Iwuji C, et al. A randomized phase II trial comparing different schedules of nab-paclitaxel (nabP) combined with gemcitabine (GEM) as first line treatment for metastatic pancreatic adenocarcinoma (PDAC). Journal of Clinical Oncology. 2017; 35 (Suppl 4): S342.

14. Barrera I, Filimon SD, Meng J, Kavan T, Rho YS, Batist G. Gemcitabine plus nab-paclitaxel use in metastatic pancreatic cancer: A study of 40 patients. Journal of Clinical Oncology. 2017; 35 (Suppl 4): S498.

15. Ahn DH, Krishna K, Blazer M, Reardon J, Wei L, Wu C, et al. A modified regimen of biweekly gemcitabine and nab-paclitaxel in patients with metastatic pancreatic cancer is both tolerable and effective: A retrospective analysis. Therapeutic Advances in Medical Oncology. 2017; 9: 75-82.

16. Kunzmann V, Martens UM, Alguel H, Siveke JT, Goekkurt E, Pelzer U. Secondary resectability in locally advanced pancreatic cancer (LAPC) after nab-paclitaxel/gemcitabine- versus FOLFIRINOX-based induction chemotherapy: Interim results of a randomized phase II AIO trial (NEOLAP). Journal of Clinical Oncology. 2018; 36 (Suppl 4): S348.

17. Taieb J, Rinaldi Y, Pointet A-L, Barbier E, Khemissa F, Gratet A. Gemcitabine plus nab-paclitaxel until progression or given sequentially with 5-fluorouracile plus irinotecan (FOLFIRI.3) for first-line treatment of metastatic pancreatic ductal adenocarcinoma (mPDAC): A randomized phase II study (PRODIGE 37-FIRGEMAX). Journal of Clinical Oncology. 2018; 36 (Suppl 15): S4107.

18. Kang J, Hwang I, Yoo C, Kim K-p, Jeong JH, Chang H-M, et al. Nab-paclitaxel plus gemcitabine versus FOLFIRINOX as the first-line chemotherapy for patients with metastatic pancreatic cancer: retrospective analysis. Investigational New Drugs. 2018; 36: 732-41.

19. Kokkali S, Drizou M, Tripodaki E, Stefanou D, Magou E, Zylis D, et al. Updated results of biweekly gemcitabine/nab-paclitaxel as first-line treatment for advanced pancreatic cancer. Annals of Oncology. 2018; 29 (Suppl 5): S142.

20. Mare M, Munao S, Germana S, Colarossi C, Sciacca D, Giuffrida D, et al. Nab-paclitaxel plus gemcitabine in the treatment of metastatic pancreatic cancer: our experience. Annals of Oncology. 2017; 28 (Suppl 6): mdx425.029.

21. Sasaki T, Kanata R, Saito K, Yamada I, Matsuyama M, Ozaka M, et al. Gemcitabine and nab-paclitaxel combination therapy for the treatment of metastatic pancreatic cancer. Annals of Oncology. 2016; 27 (Suppl 7): mdw521.071.

22. Ryu JK, Yoo M, Lee SH, Kim YT. Efficacy and safety of nab-paclitaxel in combination with Gemcitabine in Korean patients with metastatic pancreatic cancer. Pancreatology. 2018; 18: S64-S5.

23. Pacheco-Barcia V, France T, Zogopoulos G, Bouganim N, Donnay O, Alcindor $\mathrm{T}$, et al. Gemcitabine plus nab-paclitaxel versus modified FOLFIRINOX as first line chemotherapy in metastatic pancreatic cancer: A comparison of toxicity and survival. Annals of Oncology. 2018; 29 (Suppl 5): mdy151.63.

24. Vivaldi C, Cappelli C, Donati F, Fornaro L, Musettini G, Pasquini G, et al. Analysis of early tumor shrinkage and depth of response in metastatic pancreatic cancer patients treated with first-line modified FOLFIRINOX or gemcitabine + nab-paclitaxel. Annals of Oncology. 2018; 29 (Suppl 5): mdy151.8.

25. Giordano G, Vaccaro V, Lucchini E, Bertocchi P, Bergamo F, Musettini G, et al. Analysis of prognostic factors in advanced pancreatic cancer (APDAC) patients (pts) undergoing to first-line nab-paclitaxel (Nab-P) and gemcitabine (G) treatment. Journal of Clinical Oncology. 2015; 33 (Suppl 3): S412.

26. Hashimoto $Y$, Takahashi H, Ohno I, Imaoka H, Sasaki M, Umemoto K. Clinical outcomes of gemcitabine plus nab-paclitaxel $(\mathrm{GnP})$ in initially diagnosed locally advanced pancreatic cancer. Journal of Clinical Oncology. 2018; 36 (Suppl 4): S407.

27. Bachet JB, Hammel P, Desrame J, Chibaudel B, Debourdeau P, Dauba J, et al. Nab-paclitaxel plus gemcitabine or plus simplified LV5FU2 as firstline therapy patients with metastatic pancreatic adenocarcinoma. A GERCOR randomized phase II study (AFUGEM). European Journal of Cancer. 2015; 51: S453-S4

28. You MS, Ryu JK, Choi YH, Choi JH, Huh G, Paik WH, et al. Efficacy of Nab-Paclitaxel Plus Gemcitabine and Prognostic Value of Peripheral Neuropathy in Patients with Metastatic Pancreatic Cancer. Gut Liver. 2018; 12: 728-35.

29. Watanabe $\mathrm{K}$, Hashimoto $\mathrm{Y}$, Umemoto $\mathrm{K}$, Takahashi $\mathrm{H}$, Sasaki M, Imaoka $\mathrm{H}$, et al. Clinical outcome of modified FOLFIRINOX versus Gemcitabine plus nab-paclitaxel as first line chemotherapy in metastatic pancreatic cancer. Journal of Clinical Oncology. 2017; 35 (Suppl 4): S438.

30. Goldstein D, El-Maraghi RH, Hammel P, Heinemann V, Kunzmann V, Sastre J, et al. nab-Paclitaxel Plus Gemcitabine for Metastatic Pancreatic Cancer: Long-Term Survival From a Phase III Trial. Journal of the National Cancer Institute. 2015; 107: dju413

31. Xu R, Yu X, Hao J, Wang L, Pan H, Han G, et al. Efficacy and safety of weekly nab-paclitaxel plus gemcitabine in Chinese patients with metastatic adenocarcinoma of the pancreas: a phase II study. BMC cancer. 2017; 17: 885 .

32. Cho IR, Kang H, Jo JH, Lee HS, Chung MJ, Park JY, et al. Efficacy and treatment-related adverse events of gemcitabine plus nab-paclitaxel for treatment of metastatic pancreatic cancer "in a Korean" population: A single-center cohort study. Seminars in Oncology. 2017; 44: 420-7.

33. Ko AH, Murphy PB, Peyton JD, Shipley DL, Al-Hazzouri A, Rodriguez FA, et al. A Randomized, Double-Blinded, Phase II Trial of Gemcitabine and Nab-Paclitaxel Plus Apatorsen or Placebo in Patients with Metastatic Pancreatic Cancer: The RAINIER Trial. Oncologist. 2017; 22: 1427-+.

34. Conroy T, Desseigne F, Ychou M, Bouche O, Guimbaud R, Becouarn Y, et al. FOLFIRINOX versus gemcitabine for metastatic pancreatic cancer. $\mathrm{N}$ Engl J Med. 2011; 364: 1817-25.

35. Ventriglia J, Laterza MM, Savastano B, Petrillo A, Tirino G, Pompella L, et al. Safety and efficacy of gemcitabine/nabpaclitaxel in elderly patients with metastatic or locally advanced pancreatic adenocarcinoma: A retrospective analysis. Annals of Oncology. 2017; 28 (Suppl 5): mdx369.139.

36. Kang J, Hwang I, Yoo C, Kim KP, Jeong JH, Chang HM, et al. Nab-paclitaxel plus gemcitabine versus FOLFIRINOX as the first-line chemotherapy for patients with metastatic pancreatic cancer: retrospective analysis. Investigational New Drugs. 2018; 36: 732-41.

37. Chiorean EG, Von Hoff DD, Reni M, Arena FP, Infante JR, Bathini VG, et al. CA19-9 decrease at 8 weeks as a predictor of overall survival in a randomized phase III trial (MPACT) of weekly nab-paclitaxel plus gemcitabine versus gemcitabine alone in patients with metastatic pancreatic cancer. Annals of oncology : official journal of the European Society for Medical Oncology. 2016; 27: 654-60

38. Dhir M, Zenati MS, Hamad A, Singhi AD, Bahary N, Hogg ME, et al. FOLFIRINOX Versus Gemcitabine/Nab-Paclitaxel for Neoadjuvant Treatment of Resectable and Borderline Resectable Pancreatic Head Adenocarcinoma. Annals of surgical oncology. 2018; 25: 1896-903.

39. Balaban EP, Mangu PB, Khorana AA, Shah MA, Mukherjee S, Crane CH, et al. Locally Advanced, Unresectable Pancreatic Cancer: American Society of Clinical Oncology Clinical Practice Guideline. J Clin Oncol. 2016; 34: 2654-68.

40. Gemenetzis G, Groot VP, Blair AB, Laheru DA, Zheng L, Narang AK, et al. Survival in Locally Advanced Pancreatic Cancer After Neoadjuvant Therapy and Surgical Resection. Ann Surg. 2018; [Epub ahead of print].

41. Suker M, Beumer BR, Sadot E, Marthey L, Faris JE, Mellon EA, et al. FOLFIRINOX for locally advanced pancreatic cancer: a systematic review and patient-level meta-analysis. Lancet Oncol. 2016; 17: 801-10.

42. Hammel P, Huguet F, Laethem J-Lv, Goldstein D, Glimelius B, Borbath I, et al. Comparison of chemoradiotherapy (CRT) and chemotherapy (CT) in patients with locally advanced pancreatic cancer (LAPC) controlled after 4 months of gemcitabine with or without erlotinib: Final results of the international phase III LAP 07 study. Pancreatology. 2013; 13: S89-S.

43. Zhong J, Switchenko J, Behera M, Kooby D, Maithel SK, McDonald MW, et al. Chemotherapy with or Without Definitive Radiation Therapy in Inoperable Pancreatic Cancer. Ann Surg Oncol. 2018; 25: 1026-33.

44. Yamada S, Fujii T, Yokoyama Y, Kawashima H, Maeda O, Suzuki K, et al. Phase I study of chemoradiotherapy using gemcitabine plus nab-paclitaxel for unresectable locally advanced pancreatic cancer. Cancer Chemotherapy and Pharmacology. 2018; 81: 815-21.

45. Kim $\mathrm{CH}$, Ling DC, Wegner RE, Flickinger JC, Heron DE, Zeh $\mathrm{H}$, et al. Stereotactic body radiotherapy in the treatment of pancreatic adenocarcinoma in elderly patients. Radiat Oncol. 2013; 8: 240. 
46. Zhong J, Patel K, Switchenko J, Cassidy RJ, Hall WA, Gillespie T, et al. Outcomes for patients with locally advanced pancreatic adenocarcinoma treated with stereotactic body radiation therapy versus conventionally fractionated radiation. Cancer. 2017; 123: 3486-93.

47. Tahara J, Shimizu K, Otsuka N, Akao J, Takayama Y, Tokushige K. Gemcitabine plus nab-paclitaxel vs. FOLFIRINOX for patients with advanced pancreatic cancer. Cancer chemotherapy and pharmacology. 2018; 82: 245-50. 